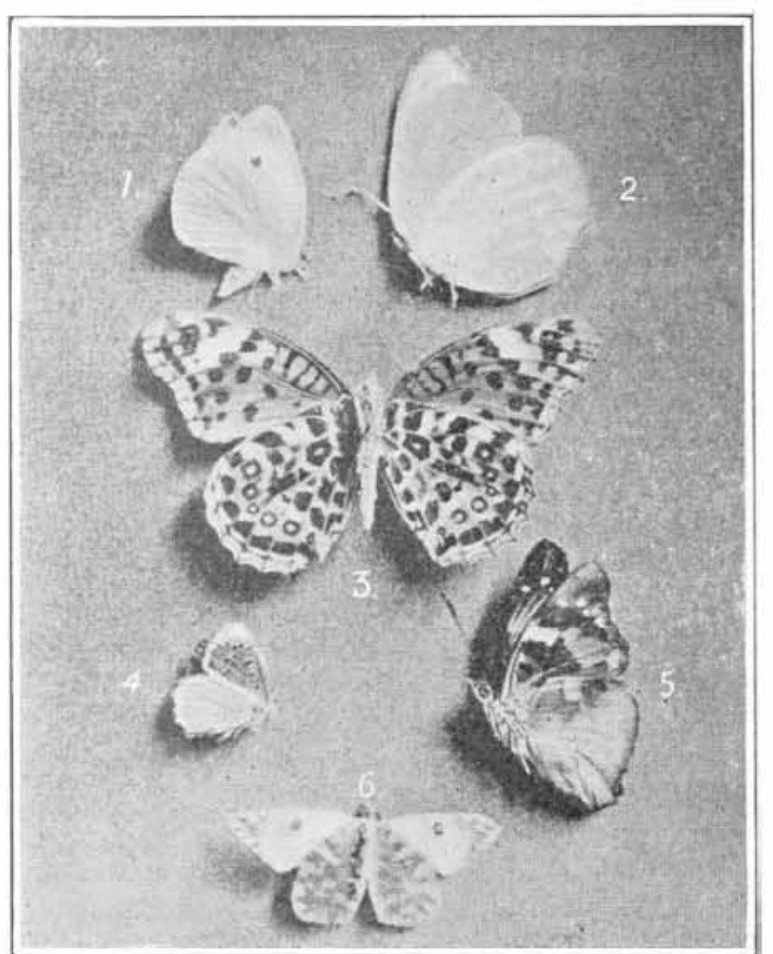

Fig. 1.-1, Large Cabbage White; 2, South European Brimstone; 3, Foreign Species; 4, Small Copper; 5, Foreigñ Species; 6, Foreign Orange Tip.

IN the case of many butterflies, when one of them alights, and intends, not merely to sun himself or display his beauties to an admiring sweetheart, but to rest for some time he first folds his wings together closely for some time, he first folds his wings together closely
back to back, and then draws his fore wings downward in such a manner that they are, as completely as possible, covered by the hind wings; and it is obvious to any observer that in very many cases the underside of the hind wings is the part so colored in various ways as to resemble the surroundings and thus conceal the creature from its enemies.

I say "as completely as possible;" for the difference in the shapes of the fore wings and hind wings prevents this covering from being quite complete. In almost all cases the hind wing is rounded, while the fore wing is more or less triangular in shape and ends in a point, and thus the tip of the fore wing remains uncovered and visible.

Now the beautiful detail which I propose to illustrate is this: That the uncovered portion of the underside of the fore wing, repeats in a great number of instances the pattern and coloring of the under surface of the hind wing and thus carries out to perfection the concealment; while the remainder of the under-surface of the fore wing, covered when at rest by the hind wing, has often quite different coloring and is in many cases of most brilliant and conspicuous hues.

As I first observed this detail in the "Orange Tip" (I prefer the ordinary English names to the scientific ones, as each butterfly has such a number of systematic synonyms), I will give that charming little herald of spring the first place in the illustrations (see Fig. 4), though it is not perhaps the best of them.

No one will, after looking at the picture, doubt for a moment the use of the peculiar pattern on the underside of the hind wing. The butterfly is settled on an umbel of wild chervil and any one who wants a specimen of an Orange Tip has only to wait in a lane full of that plant and he will soon find one coming along, if it be

* Reproduced trom Knowledge.

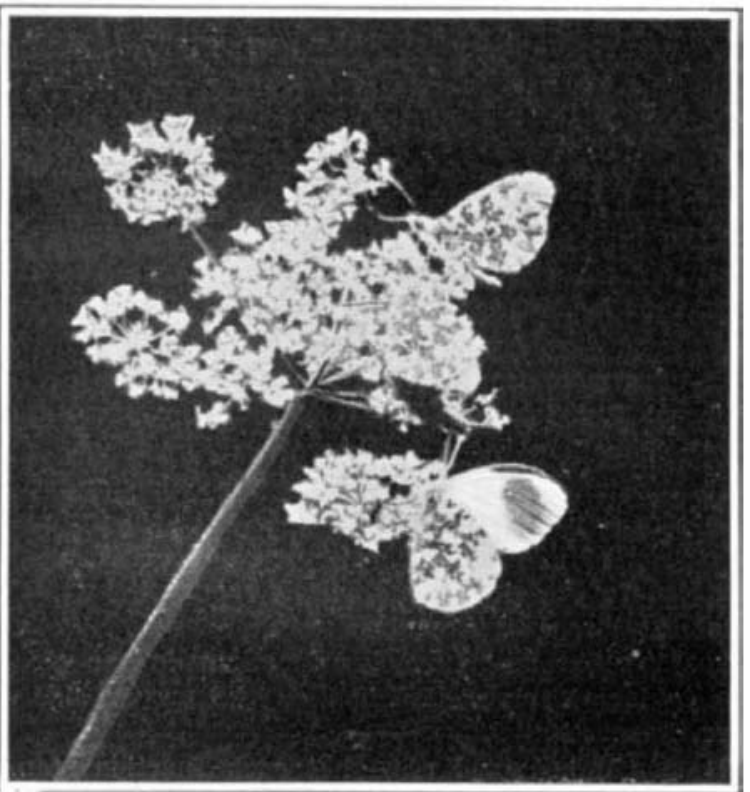

lig. 4.-Orange Tip Butterflies on Wild Chervil

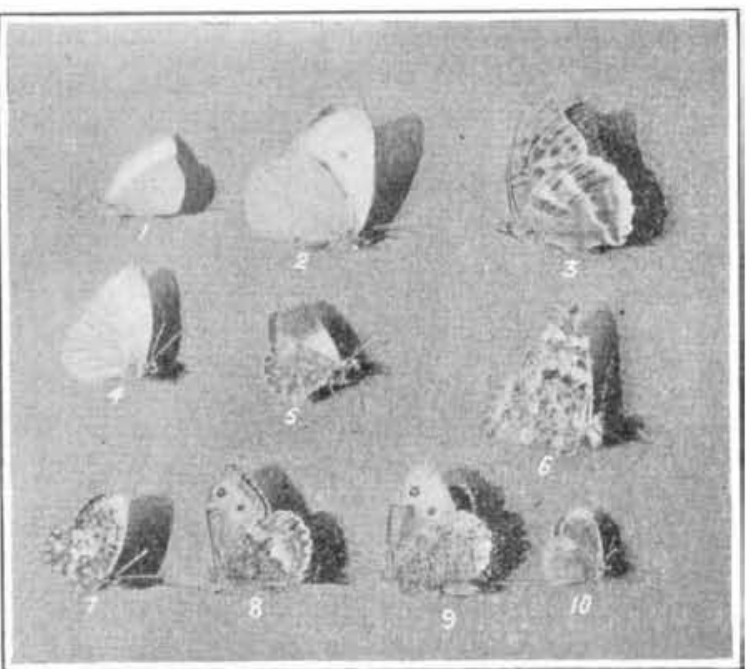

Fig. 2.-1 and 4, Green-veined White; 2, Small Cabbage White; 3, Silver-washed Fritillary; 5, Orange Tip; 6, Painted Lady; 7, Pearl-bordered Fritillary; 8 and 9, Grayling; 10, Small Heath.

\section{The Coloration of Butterflies}

\section{Some Striking Examples of Protective Mimicry}

By, Rev. F. Bennett, M. A., Oxon.

May or June, though he may look in vain for one in the adjoining fields.

The resemblance is so complete that the butterfly in the midst of the umbel can hardly be discovered at all, and if the photograph could have been done in colors, the concealment would only have been more completel shown; the white parts of the wing representing th flowers, and the green parts representing the stalks, involucres and other green parts of the plant as well as the background of grass or hedge in the distance. The conspicuousness of the specimen whose wings are not drawn together proves the point to perfection.

Now the pattern (we might call it the design) on the hind wing which so completely conceals the restin Orange Tip is, it will be seen, continued at the tip of the fore wing and this continuation of the pattern is precisely outlined by the very curve which the end of the hind wing makes. They fit exactly! But the orange spot is completely concealed.

But there is more than this, for it will be observed that the front margin and even the thin, sharp edg of the fore wings (this edge being often somewhat rounded) have markings of the same type, so that, looked at in front, the protective resemblance to the flower is continued, in place of a white line which would otherwise appear and be dangerous, so minute are Nature's details in this matter.

But there is yet even more. It will be seen on examination that the pattern on the tip of the fore win is somewhat run into lines (as may be seen in Fig. 2, No. 5). This repeats a tendency to the same thing at the margin of the hind wing; and it thus imitates in connection with the background of green, and just at the right place, the appearance which the edges of the umbel present.

The completeness and exactness of the continuation of the pattern are even more clearly shown in the butterfly (Fig. 1, No. 6) a foreign relative, I think, of our Orange Tip. In this the imitation of the pattern on the hind wings is much more exact, as will be easily seen

The economy of Nature is wonderfully illustrated in these cases, since there is precisely as much as needed of the pattern on the fore wings and no more, the curves fitting so truly.

Just the same sort of pattern and its repetition are seen in the "Bath White" (Fig. 5)

A brief review of the illustrations will sufficiently demonstrate the use of this arrangement of color and markings.

Fig. 1, No. 1, and Fig. 2, No. 2, show the large and small Cabbage Whites. In both the greenish-yellow of the hind wing is repeated at the tip of the fore wing. The color is close to that of the cabbage flower, but it more closely still resembles that of a dead piece of cabbage leaf, which, when faded, takes exactly this color.

It may be noticed that a "small white" will $\operatorname{som}_{\theta^{-}}$

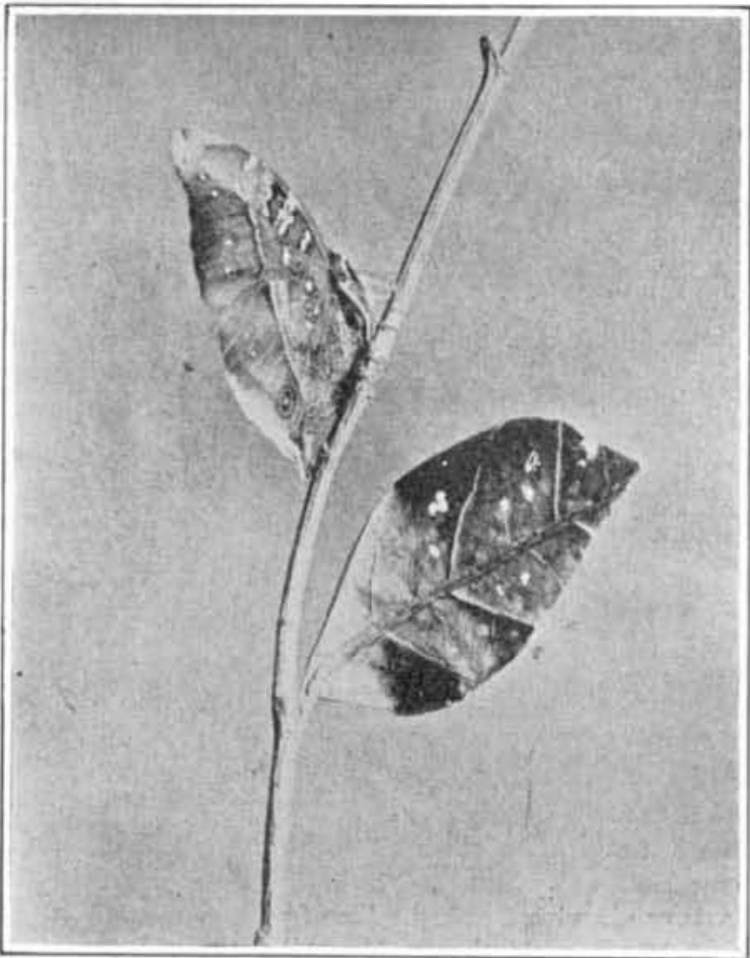

F'g. 3.-Leaf Butterfly.

times place itself sideways, so that its wings lie flat on the leaf. The same is true of "Meadow Browns," which sometimes thus place themselves on the ground. Such a position would aid in the concealment and (in the absence of any other explanation of this curious custom) would seem to be adopted for that reason.

Fig. 1, No. 2, is a South European form of the "Brimstone" and the greenish-yellow of the hind wing is repeated at the tip and along the front margin of the fore wing, while the folding conceals a brilliant patch of orange. This repetition along the front margin would be useful while the folding of the fore wing behind the hind wing was in progress, or was incomplete.

Fig. 1, No. 3, is a foreign butterfly in which the silver spots and olive green of the underside of the hind wings are repeated at the tip of the fore wing, while the rest of the fore wing, eoncealed when at rest, is of a bright red-brick color with black spots, and a conspicuous white bar.

Fig. 1, No. 4, is the "Small Copper," in which the gray of the hind wing is continued at the tip of the fore wing, and the brilliant color and spots hidden by the folding over.

Fig. 1, No. 5: Underside of a foreign butterfly. The coloration of the hind wing, a dusky brown, is repeated at the tip, and a brilliant yellow bar concealed. Fig. 2, Nos 1 and 4, are "Green-veined Whites" It is well known that these vary very much, so that they have been divided by some authors into several species, and the curious thing is that, as the colors and the markings of the hind wing vary, so precisely do the colors and marking vary at the tip of the fore wing.

Fig. 2, No. 3, is the "Silver-washed Fritillary," in which the green of the hind wings is repeated at the tip with sometimes a little of the silver. In other fritillaries, more or less of the same arrangement will be found, and in the "Pearl-bordered Fritillary" (see Fig. 2, No. 7), the brick red patches which are on the hind wing are more or less repeated, with part of the paler yellow at the tip of the fore wing and only there. I do not know what this red brick may represent, but it is evident that to have a patch of a different color

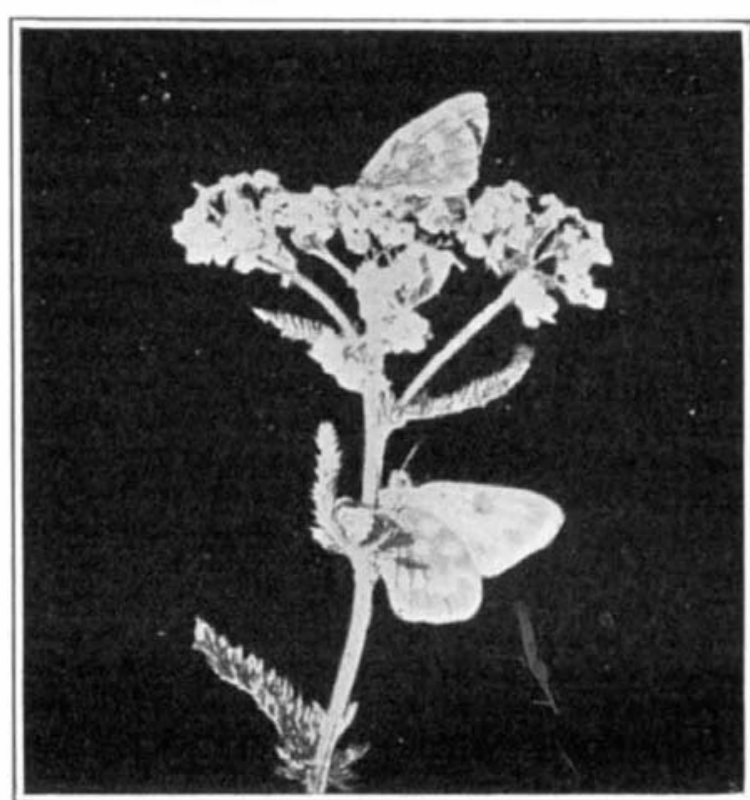

Fig. 5.-Bath White Butterflies. 
at the tip of the fore wing would render the creature much more conspicuous.

Fig. 2, No. 6, is the "Painted Lady," in which the brown and gray of the fore wings are repeated at the tip of the fore wing, while the brilliant pink and yellow are concealed.

Fig. 2, Nos. 8 and 9, are two specimens of the "Grayling" or "Rock-eyed Underwing." The markings of the hind wing vary a good deal and in exactly the same manner do the markings of the fore wing vary to correspond, both at the tip and along the front margin.

Fig. 2, No. 10, is the common little butterfly variously called "Small" Heath," and "Least Meadow Brown." In this, when closed, the brown and grav are repeated at the tip, while the yellow and orange and the eye spot of the fore wing are concealed.

Fig. 6 is the "Marbled White," in which the pale and thin-lined pattern of the hind wing is repeated at the tip of the fore wing, while the darker coloring of the fore wing is concealed. This is more obviou in the American form, which has a brown-lined pattern on the hind wing exactly repeated at the tip of the fore wing. I do not know what the markings in the American species may represent, but it may not be a wild conjecture that the object of the pattern in the English butterfly is indicated by the surroundings which I have given it, and that it conceals the creature by imitating the dead panicles of grass which abound in those dry places near woods where the butterfly is so of ten to be found, and on which it frequently settles. We do not see the full force of any argument till we look at it . (so to speak) from the opposite side; and this detail in protective coloration is clearly brought out by the cases where it is not needed. Contrast, for example, the underside of the wings of the "Comma," "Large Tortoise-shell," "Peacock," where the protective coloring is spread over the whole of both hind wings, with the repetition of the hind wing pattern in "Smal Tortoise-shell," "Red Admiral," and so on.

It is curious that in Anosia menippe Hübner, a butterfly which is now sometimes caught in England and which is said to be protected by a nasty taste, the paler color of the hind wings is repeated in a patch paler color of the hind wings is repeated in a patch at the tip of the fore wings, while the color of the rest
of the fore wings resembles that on the upper surface. of the fore wings resembles that on the upper surface. yellow may not in these cases be warning as had been supposed. On that supposition it would seem difficult to find a reason (and a reason must exist) for this curious bit of repetition.

Figs. 3 and 7 are two species of the leaf butterflies whose likeness to dead leaves is now so familiar to us all. These, of course, do not fold the fore wing behind the hind wing, and there is, therefore, no reason for any repetition of the hind wing pattern. The tip merely displays a little imitation of a fungus.

The head of the insect is placed between the wings and hidden, when it is at rest. This puts out of sight the conspicuous eye, which would perhaps tell a tale, so complete are the arrangements for concealment.

An interesting point here occurs; most dead leave hang down; do the Kallimas take that position or do the leaves of the trees on which they rest retain the upright position when dead? I have not seen this noticed by the authors on the subject.

The Nyctalemon Moth of the Aindaman Islands evidently represents a dead leaf, as it has an imitation of a midrib throwing an imitation shadow on one side, and has also a tail to represent the stalk. But most moths appear to rely on the upper surface of their wings for consealment. Many of them, as the socalled "Underwings," have their brilliant colors on the upper surface of the hind wings and conceal these, when they are resting, with re protectively colored. This, no doubt, applies to

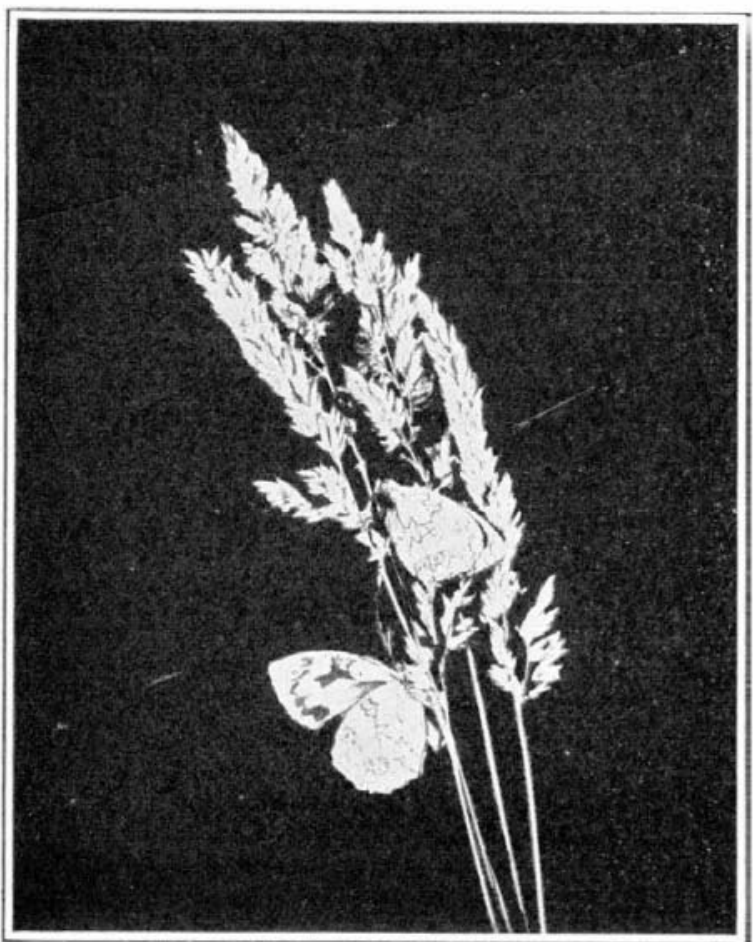

Fig. 6.-Marbled White Butterflies on Dead Panicles of Grass.

some butterflies whose wings are colored in the same way.

The "Skippers" form a group half-way between the Moths and the Butterflies. Our "Dingy Skipper" is said to rest with the wings folded over its back in the exact position of a noctuid. Now the "Dingy Skipper"

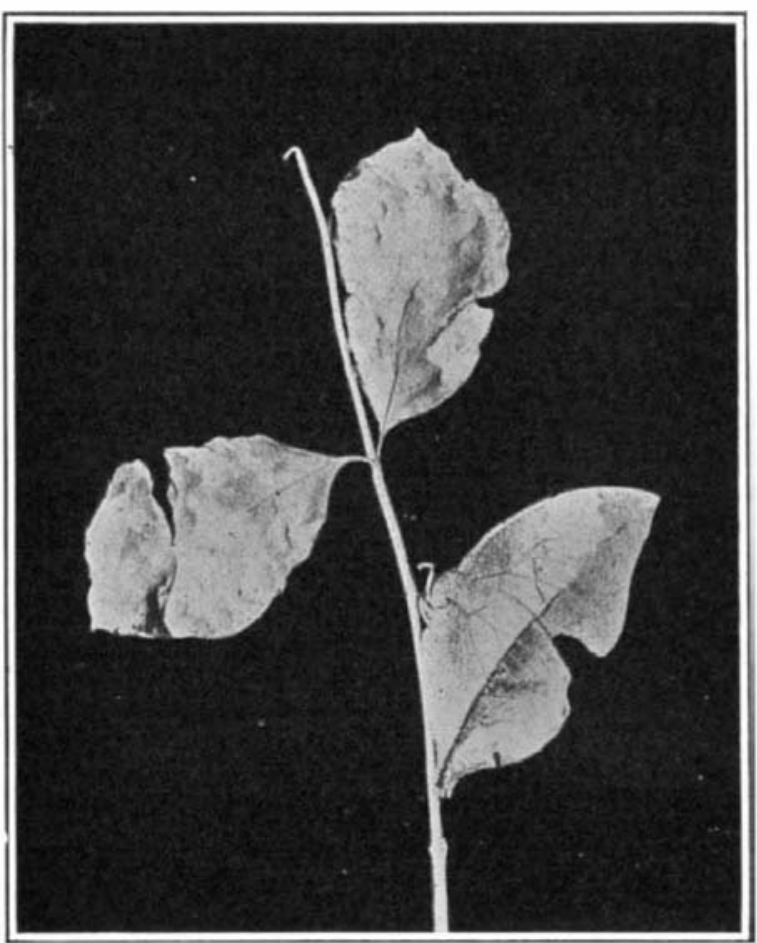

Fig. 7.-I Leaf Buttertly, Kallimo. shows no sign of any repetition at the tip of the fore wing of any special color on the hind wing; but the "Large" and the "Small" Skippers both show the usual repetition of the hind wing coloring. How they I am not certain.

Every one will, I am sure, agree that sufficient proof has been given of the existence of this curious and minute arrangement of Nature for the protection of these little creatures; but it is in all such cases to be noticed that there is of ten some little imperfection in the work of protection. It seems as if Nature in Evolution was sometimes actuated by two or more contradictory plans, which she has to harmonize as best she can. There is the tendency to some protective resemblance, but there is also the tendency to brilliance of color or design for the purpose of recognition by or attraction of the opposite sex; and, lastly, there seems to be a real tendency to develop color in special places, as, for example, along the nervures of Lepidoptera, as in the "Green-veined White," "Blackveined White," and so on, a tendency which is also, no doubt, responsible for the frequent coincidence of markings on both sides of the wings, as in the "Brimstone," "Clouded Yellow," "Apollo," and so on.

Such tendencies are obviously opposing ones; and one is often lost in admiration at the wonderful methods by which Nature has reconciled them, often producing the most perfect protection and at the same time the greatest beauty. It is conceivable also that in such a case as that of Danais chrysippus the upper side of the wings may have warning colors while the under side, where the yellow of the hind wings is repeated at the tip of the fore wings, as in Anosia menippe, may be protective, to guard against inexperienced enemies who do not know thiat they are unpalatable for eating, and so would kill or injure them in mistake, just as cats kill innumerable shrews which afterward they will not eat.

This detail in coloring shows with what minuteness Nature carries out the plan of protective coloration and resemblance, and how small a piece of detail gives some advantage in the struggle for escape; for otherwise this little bit of coloring would not have con tinued. In further illustration of the minuteness observe the delicate imitation of a tear in the wing of Kallima (see Fig. 7). Only with a magnifying glass can one see that the tear is not real, and that the wing is perfect. The effect is produced by alternate black and white markings.

The success of the protective coloring is frequently forced on the attention of the butterfly hunter, who finds that the insect he has been pursuing has disappeared from his view though he knows and sees, just too late, that it has been all the while within a very small. plot of ground.

There is also another point of view which I have not seen brought forward, as to the success of this sort of protection. It is this: That an animal has no time to waste in examining objects which at closer quarters might (though a little suspicious) turn out to be really twigs or leaves; and thus a very imperfect resemblance (to our eyes who have plenty of leisure for the examination) would of ten be sufficient, and would be preserved till in process of time a more and more perfect resemblance was evolved. If one watches a bird supplying its ravenous nestlings one can easily see that it has to do the work at full speed.

If we sometimes thus placed ourselves in the position of animals, and by imagination "identified our minds" (in E. A. Poe's phrase) with theirs for awhile, we should very often comprehend Nature better and discover more of her secrets.

\section{The Evidence That Sodium Belongs to a} Radioactive Series of Elements*

\section{By F. C. Brown}

Campeell and Wood ${ }^{1}$ could not detect in the compounds of sodium any activity that was definitely greater than that common to all matter and certainly no activity one thousandth as great as that of potassium. If, therefore, sodium belongs to a radioactive series of elements, it of itself must be undergoing disintegration and at the same time be inactive so far as measurable ionizing radiations are concerned, or sodium must be a relatively inactive product resulting from a radiobe a relatively inactive product resulting from a radioactive parent. If the former is true then sodium left at rest a long period of time should diminish in amount. But if the latter presumption is true, sodium should in time form

For evidence as to these presumptions the facts of

* Abstract of a paper presented at the Evanston meeting of the Physical Society, November 30th, 1912, published in the Physical geo-chemistry are used and it is found that two separate sets of facts favor the hypothesis that sodium has been accumulating radioactively over the land durin geologic history. First an investigation of the sodium carried to the ocean by the rivers annually, and als carried to the ocean by the rivers annually, and also an investigation of the total sodium content of the ocean, seems to show that the age of the ocean and of
the earth is probably not more than $75,000,000$ years old. Joly ${ }^{2}$ and also F. W. Clarke ${ }^{3}$ after a careful con sideration of the possible sources of error deduce these figures. On the other hand if the age is based on the amounts of lead and helium associated with uranium in minerals, we find that the age is upward of a billion years. Thus far the fact seems to be that there is not as much sodium in the ocean as expected. The apparently sufficient explanation is that sodium has been accumulating radioactively over the land but not so over the ocean. Thus the rivers formerly should not have carried as much sodium as they carry at the present day.

2Phil. Mag., 6, 22, p. 357, 1911 'The Data of Geo-Chemistry, second edition, Bulletin 491 ,
N. B. G. S.
An investigation of a second set of facts also makes it convenient to put forth the hypothesis of the radioactive accumulation of sodium over the land areas. If we compare the annual additions of sodium and chlorine by the rivers, it is found that more sodium than chlorine is carried to the ocean. While an examination of the contents of the ocean water reveals much more hlorine than sodium, these two elements are compared because both are soluble in all compounds and neither is deposited in appreciable quantities in the ocean sediments. Of course this comparison only indicates that sodium has accumulated more rapidly than chlorine. So far as the argument is concerned the element chlorine itself may also have accumulated radioactively in past ages.

No other common explanation has been offered for he two distinct sets of comparative data here used. It would seem therefore worth while to make a search for the possible parentage of sodium. The parent or parents should commonly exist over the land areas, and should in all compounds be relatively insoluble in water. If, however, the parent substance has become extinct or almost extinct this search would be futile. 